\title{
Percursos e percalços na investigação da emoção na Psicologia de Vigotski
}

\section{Paths and pitfalls in the investigation of emotion in the Vigotski's Psychology Caminos y escollos en la investigación de la emoción en la Psicología de Vigotski}

Heriel $\mathrm{Luz}^{\mathrm{I}}$

Ana Lucia Martins de Souza ${ }^{2}$

Universidade Federal de Mato Grosso do Sul

Livia Gomes dos Santos ${ }^{3}$

Pontificia Universidade Católica de São Paulo

\begin{abstract}
Resumo
Neste artigo serão apresentados e discutidos aspectos do caminho trilhado pelo psicólogo bielorrusso Vigotski em seu interesse por produzir uma Psicologia Histórico-Cultural, onde a emoção fosse elevada da posição de mera coadjuvante para a de protagonista na dinâmica subjetiva. Seu interesse repousou na busca de respostas às controversas e antitéticas teorias que hora assumiram a emoção como substância imanente e hora como substrato biológico em vias de desaparecimento em sintonia com o darwinismo, mas sem proporem caminhos de superação para essa contradição. Pautado nos fundamentos do Materialismo Histórico e do Materialismo Dialético, o autor propôs-se a investigar a emoção pela síntese histórica, mostrando que o desenvolvimento das funções psicológicas superiores, dentre elas a emoção, tema desse artigo, está condicionado a sua ação mediadora da vida psíquica. As contribuições de seus estudos produziram impactos que repercutem até os dias atuais nas diferentes áreas científicas que se dedicam à investigação da emoção.

Palavras-chave: Emoção; Método histórico; Vigotski.
\end{abstract}

\begin{abstract}
This article aims to present and discuss some aspects of the path taken by Vigotski in his intention to produce a Historic-Cultural Psychology, where emotion is promoted from the position of simple adjunct to the protagonist in the subjective dynamic. His intention laid on the search for answers to controversial and antithetical theories that sometimes assumed emotion as and immanent substance and other times as a biological substrate near to disappear, without presenting ways to overcome this contradiction. Lined on the fundaments of Historic Materialism and Dialectics Materialism, the author aims to investigate emotion using the historical method, demonstrating that the development of higher psychological functions is conditioned to its mediating action of psychic life. The contributions of his studies produced impacts that reverberate until the present days in different scientific areas that are dedicated to the investigation of emotion.

Key-words: Emotion; Historical method; Vigotski.

\section{Resumen}

Este artículo tiene como objetivo presentar y discutir algunos aspectos de la trayectoria tomada por Vygotsky en su interés por producir una Psicología Histórico-Cultural, donde la emoción se eleva desde ser un simple apéndice a ser protagonista en la dinámica subjetiva. Su interés radica en la búsqueda de respuestas a las teorías polémicas y antitéticas que a veces asumieron la emoción como sustancia inmanente y, a veces, como un sustrato biológico por desaparecer, sin presentaren formas de superar esta contradicción. Alineado en los fundamentos del materialismo y la dialéctica, el autor propone investigar la emoción desde el método histórico, mostrando que el desarrollo de las funciones psicológicas superiores se condiciona a su acción mediadora de la vida psíquica. Las contribuciones de sus estudios produjeron impactos que repercuten hasta hoy en diferentes áreas científicas que se dedican a la investigación de la emoción.
\end{abstract}

Palabras-clave: Emoción; Método histórico; Vigotski.

Endereço 1: Rua Otacílio de Souza, 161 - Conj. Res. União, Campo Grande - MS, Brasil, CEP 79091-700.

Endereço 2: Pró-Reitoria de Extensão, Cultura e Assuntos

Estudantis, Cidade Universitária, s/nº, Caixa Postal 549, Campo Grande - MS, Brasil, CEP 79070-900.

Endereço 3: Rua Capitão Otávio Machado, 950 - Apto. 11B, São Paulo-SP, Brasil.

\section{Emoção: Caminhos de uma Investigação}

A busca pela compreensão dos processos psicológicos superiores, a partir da ótica do afeto e da emoção, está presente no âmbito da ciência psicológica contemporânea e em áreas nem tão diretamente ligadas a ela, e este não é um fato novo. Conforme Belli e Iñiguez-Rueda (2008) e Pinto (1998), encontram-se tentativas de estudo ou de aplicação das concepções acerca da emoção nos 
mais diversos campos, desde a neurobiologia, o marketing, a engenharia computacional, a genética, a bioenergética, dentre outras áreas do conhecimento.

Apesar da banalização do vocábulo dentro e fora do campo das ciências psicológicas, a investigação do fenômeno das emoções apontava para o desconforto das Escolas Psicológicas em assumi-lo, posto que representava o nó teórico que precisariam desatar no estudo da unidade dos Processos Psicológicos Superiores. Esse nó traduz uma herança pesada, um "Elemento Escuro", nos dizeres de Sawaia (2000, p.02), parafraseando uma expressão de Vigotski (2003), pois apontava os limites teóricos e metodológicos para a compreensão integral do psiquismo. Pelo abandono ou limites colocados ao seu estudo, outras áreas do conhecimento, correlatas ou não à ciência psicológica, assumiram tal desafio. Vigotski analisou algumas delas, fazendo um levantamento das principais pesquisas realizadas nessa temática em sua época. Vejamos, pois, as principais pesquisas apontadas pelo psicólogo bielorrusso.

Embora os estudos de Darwin (1809-1882) sobre a Origem das Espécies contassem com mais de 50 anos desde sua primeira publicação, seu nome ainda retumbava no meio acadêmico à época de Vigotski. Os princípios gerais do evolucionismo, pautados na mutação e na seleção natural como propiciadoras do processo evolutivo das espécies permearam esses estudos, notadamente um dos últimos estudos darwinianos, analisado por Vigotski. Neste trabalho Darwin (1902) faz uma correspondência entre as expressões humanas e aquelas instintivas presentes no reino animal. Para tanto, ele utilizou gravuras, comparando diversas imagens de animais e de diferentes povos, em contextos variados. Ele notou que havia semelhanças entre a expressão dos animais e dos homens, em conformidade com a tradição daquele momento que apregoava que a reação emocional traduzia-se em uma expressividade facial, ou seja, exteroceptiva.

O objetivo dos estudos empreendidos por Darwin era o de responder às teses de Charles Bell (17741842), expressadas em seus ensaios: Anatomia $e$ Fisiologia da Expressão e The Nervous System of the Human Body de 1830, cujas ideias eram correntes até aquele momento. Charles Bell recorreu às explicações fisiológicas, mas nem por isso abandonou sua educação escolástica que ficou evidenciada em todo o seu estudo para a compreensão da atividade motora da expressão facial. Para ele essas expressões refletiam uma disposição do espírito. Bell (1830) via a execução de determinada expressão facial como resultado de contrações de músculos da face com propriedades espirituais específicas criadas no homem por vontade divina. É notável, no entanto, já nesse período a agudeza do fisiologista em enxergar a correlação entre as expressões faciais e outras alterações, como o ritmo cardíaco e respiratório - interoceptivo, percebendo a ligação entre sensações internas, estímulos externos e resposta a esses estímulos. Para o darwinismo, porém, a resposta ao problema da manifestação motora da emoção deveria ser buscada na própria condição animal e em sua reação aos estímulos do meio, prescindindo de explicações teológicas e sem privilegiar o homem em relação aos outros animais. E foi a isso que ele se propôs.

A busca darwiniana, entretanto, não rompeu como se pretendia o elo com a visão escolástica, fortemente presente na ciência da época, mas corroborou-a sob uma lógica naturalista-evolucionista. Isso porque, seguindo a tradição do pensamento escolástico e cartesiano, manteve-se a dualidade entre as substâncias corpo e alma. Ao mesmo tempo em que ampliou o campo científico, a teoria darwiniana manteve a égide do racionalismo judaico-cristão presentes na lógica que guiarão seus três princípios gerais da expressão, a saber: a) Primeiro Princípio: atos úteis são selecionados e transmitidos por herança; b) Segundo Princípio: sinais convencionados são expressões naturais que traduzem impulsos opostos; c) Terceiro Princípio: a ação direta sobre a economia da excitação do sistema nervoso independe da vontade e, em parte, do costume, ou seja, resultam da própria constituição do sistema nervoso. Esses três princípios apontados por Darwin (1902), sobretudo o terceiro, sintetizam de forma clara sua concepção naturalista das emoções.

As pesquisas darwinianas abriram caminho para o estudo das emoções, e também expuseram as dificuldades em percorrê-lo. Mesmo que Darwin centrasse-se, como aponta o Terceiro Princípio de sua teoria das emoções, na constituição do sistema nervoso como sede e chave à compreensão das emoções, os demais princípios demonstram o papel, ainda que secundário, que o costume e o hábito desempenham em sua constituição, até chegarem à sua condição reflexa.

Se por um lado permanece na teoria darwiniana a convicção de que a emoção é um substrato biológico animal, que em conformidade com o pensamento escolástico precisaria ser expurgado para que a razão pudesse se desenvolver amplamente, por outro perseverava a necessidade de que se compreenda sua gênese, na direção da ancestralidade do homem, por meio da qual se poderia refazer positivamente $o$ sentido de seu desenvolvimento filogenético.

Tanto em um como noutro caminho, a emoção é assumida como um rudimento, uma ação retrospectiva que indica a animalidade humana em oposição a sua racionalidade. O corpo, sede da emoção, é antitético à razão, porque é ele que, no percurso positivo da evolução, transportou os aspectos rudimentares da emoção. Depreende-se de Darwin (1902) que a evolução positiva da razão humana extinguiria as emoções. Entretanto, a previsão feita pela teleologia 
da teoria darwiniana ainda não se cumpriu. A criança e o adulto ainda têm de lidar com as emoções e o homem contemporâneo demonstra ser dirigido por elas tanto quanto seus ascendentes.

Se, como propunha a teoria darwiniana, a emoção estaria em vias de desaparecimento, as teorias psicológicas optaram por abdicar de seu estudo, reservando esse papel àquelas ciências que se ocupam dos animais, para quem a emoção cumpriria uma função primordial de gatilho para fuga ou ataque, para a garantia da sobrevivência das espécies. Essa necessidade no homem seria agora secundária, visto que recorreria à razão para a garantir sua existência, prescindindo, portanto da função que a emoção desempenha nos demais animais. Caberia, assim, pelos recursos oferecidos pela psicologia, conter suas manifestações, controlá-las, debilitá-las ou mesmo de eliminá-las, primeiramente na criança e posteriormente nas pessoas com alguma debilidade ou patologia, - sujeitos que por alguma razão de ordem biológica ou social seriam incapazes de conduzirse pela razão. Conforme Neubern (2000), coube assim à psicologia simplificar e eliminar o fenômeno antes mesmo de compreendê-lo. Tal afirmação seria anacrônica, caso não se considerem as várias exceções postas naquele momento, dentre essas se destacaram os trabalhos psicofisiológicos de James (1842-1910) e Lange (1834-1900).

Cornelius (2000) assevera que enquanto o darwinismo preocupou-se com a expressão motora das emoções - sua exterocepção -, James, por sua vez assumiu a interocepção, buscando compreender a experiência afetiva, e ainda como Darwin (1902), partindo da emoção como uma sequência de reações automática do corpo, cuja função seria a de garantir sua sobrevivência e preservação. Essa disposição expressaria um feixe de comandos predispostos no Sistema Nervoso Central e sua expressão seria um exemplo dessa disposição básica, independentemente da reação desencadeada, fosse ela comportamental, visceral, etc. A percepção dessa experiência seria resultante desse movimento automático dos organismos e a diversidade de reações ocorreria pela necessidade de adaptação às mais diversas condições. Convergem nesse mesmo sentido os estudos de Lange (1834-1900), contudo este partiu das reações vasomotoras.

A conclusão a que chegam esses dois autores, agora aparentemente livres de toda escolástica de Charles Bell, demonstra serem semelhantes quanto ao seu princípio. Bell (1830) atribuía aos movimentos expressivos dos músculos a preponderância sobre a gênese das emoções, enquanto Darwin fez o caminho inverso, partiu da disposição para então investigar as manifestações de seus movimentos expressivos. Concordando então com Bell, James (1842-1910) e Lange (1834-1900) assinalaram que é na resposta à reação reflexa que se encontra a experiência emotiva.
Nesse sentido, inverte-se o caminho proposto pelo darwinismo para a compreensão das emoções. Agora o sentido é da reação reflexa à percepção dessa reação e à consequente sensação da emoção. De acordo com essa proposta, então, ao se inibir o gatilho ou a continuidade dessa ação reflexa, confrontando-a com outra manifestação, essa experiência emocional cederia lugar a uma nova. Por exemplo, ao provocar riso em alguém que se encontra apático, produzir-seia uma sensação de alegria que suplantaria aquela da apatia. Em linhas gerais, está-se alegre porque se ri e não o contrário.

Vigotski (2003b) destaca a repercussão desses estudos de James (1842-1910) e Lange (1834-1900), que provocou diversas Escolas à tentativa de desmentir esses resultados. E, comentando as conclusões dos dois estudiosos, afirmou que suas teorias são bastante completas e elaboradas, dando conta de um aspecto crucial das pesquisas daquele momento: o da necessidade de uma fundamentação científico-natural biológica para as reações emocionais, sem os limites postos por aquelas teorias incapazes de explicar por que ainda que primitivas, essas reações perseveraram no homem.

Outro elogio à proposta de James (1842-1910) e Lange (1834-1900) é feito por Cornelius (2000), por seu distanciamento das explicações escolásticas. Embora se aproximem da lógica explicativa de Bell (1830) e da metodologia materialista de Darwin (1902), fundamentaram seus estudos no naturalismo e buscaram no corpo as explicações para as reações emotivas, diferentemente dos anteriores, que insistiam numa ação substancialista das emoções. Vigotski (2003) por sua vez, não comunga de tal posição, sobretudo em relação a James, afirmando que, embora sua teoria, até certo ponto baseasse-se no método espontâneo, ela conduzia-se em confronto com o materialismo. E mesmo o próprio James, nos dizeres de Vigotski (2003), afirmava peremptoriamente que suas pesquisas não se enquadravam nesse modelo. Devido ao próprio desenvolvimento a que chegou sua pesquisa, James foi conduzido à bifurcação no estudo das emoções: de um lado as emoções como função inferior, biológica; e de outro as que corresponderiam à função superior, psicológica.

Para resolver esse limite metodológico, Vigotski (2003) afirma que James se utilizara de seu pragmatismo e do recurso darwinista e atribuíra aos órgãos inferiores dupla função - de responder aos afetos exteriores e de emocionar-se-, e ao cérebro a função única de pensar. Assim, ampliando a dicotomia entre pensamento e afeto, pela localização anatômicofisiológica, James acreditava ter resolvido o impasse. Não obstante, a proposta de James não resolveu a dualidade mantida por Bell (1830) e Darwin (1902), mas a acirrou.

É tributária de James-Lange grande parte da série de teorias idealistas sobre as emoções, que se 
apropriaram da resolução daquela parte do problema com os quais os idealistas tinham de lidar, sobretudo quanto ao papel das reações motoras que acompanham os estados emotivos. Tais respostas, para eles, seriam reflexos da condição animal, todavia a manifestação superior continuou como sendo um fenômeno espiritual ou anímico.

Se no caso de Bell (1830) a tomada de um aspecto interno das emoções e sua localização na musculatura facial representou um avanço, o mesmo não se aplicaria a James-Lange, porque encobrindo a manifestação da emoção, que migrou para o interior do corpo, criou-se também uma ruptura e distinção entre os aspectos internos e os externos, privilegiando aqueles em detrimento destes. Sendo assim, a constituição e expressão emocional seriam eminentemente exteriorização corpórea, ainda que encoberta, e sua gênese e desenvolvimento só poderiam ser assumidos na investigação e aprofundamento dos processos viscerais desse corpo. Por fim, a teoria James-Lange sacraliza definitivamente a secção entre intelecto e emoção, ao reservaram às vísceras o lugar para emoção e ao cérebro o lugar para o pensamento. Assim, separada da totalidade dos fenômenos psicológicos, a emoção passou a ser um estado dentro de outro.

A realocação do centro das emoções nas vísceras colocou-a numa posição subalterna em relação ao pensamento e esse fato também se refletiu em sua hierarquia topológica. Para Vigotski (2003), a teoria James-Lange fechou ainda mais a porta para a compreensão do desenvolvimento da vida emocional. $\mathrm{O}$ resquício de desenvolvimento mantido na teoria de Darwin perdeu-se em James-Lange e com ele a possibilidade da compreensão da gênese da emoção e do aparecimento de novas emoções. Nem por isso Vigotski (2003) desqualifica aqueles pesquisadores, tendo em vista a riqueza experimental que suas pesquisas e a de seus sucessores propiciaram. Acerca das investigações de seus sucessores, algumas merecem destaque, dentre elas as do fisiologista americano Walter B. Cannon (1871-1945).

Esse notório fisiologista em seu livro Bodily changes in pain, hunger, fear and rage: an accout of recerches into the function of emotional excitement (1916), expos os quatro anos de estudos desenvolvidos conjuntamente com um grupo de pesquisadores da Universidade de Harvard. Nesse período, realizou pesquisa com vários animais analisando diversos aspectos fisiológicos. O resultado a que chegou foi a de que a reação emocional produz uma série de hormônios responsáveis pela superativação do organismo. As funções viscerais são hiperestimuladas, potencializando o organismo para executar uma dada ação. Todavia, as diferentes reações humorais não traduzem e nem especificam o tipo de emoção advinda a partir disso. Tal conclusão esbarra nas hipóteses de James-Lange, para quem essas ações reflexas definiriam a qualidade da emoção. As pesquisas posteriores de Cannon romperam em definitivo com aquela proposta pelos outros dois pesquisadores, principalmente na série de pesquisas realizadas em conjunto com Arturo Rosenblueth sobre neurotransmissores. Vale citar esses trabalhos: $A$ comparative study of sympathy and adrenine (1935), The chemical mediation of sympathetic vasodilatador nerve impulses (1935) e Automatic neuro-effector systems (1937).

Apesar de não acompanhar os últimos trabalhos de Cannon, Vigotski (2003) já observava a postura diametralmente oposta de suas pesquisas, em relação às de James, quanto à demonstração da manifestação dos estados emocionais, mesmo quando as ações vegetativas correspondentes não se apresentavam. $\mathrm{O}$ oposto dessa afirmação, nas séries de experimentos de Cannon (1916) com animais também se mostraram falsas. Provocar uma reação corporal característica da emoção não fez com que tal emoção se apresentasse, o que contrariou os achados de James-Lange. E o que apareceu nos experimentos com animais também provou ser verdadeiro para o ser humano. A aplicação de hormônios sintéticos ou sua retirada, a fim de provocar essa ou aquela emoção, apenas aproximava as sensações dos traços psicológicos da emoção genuína, mas a apercepção psicológica desta continuava ausente. Houve, todavia, uma diferença significativa nas pesquisas com animais e com humanos que deve ser destacada: enquanto nos animais a introdução de substâncias alheias ao corpo não foi capaz de provocar essa ou aquela emoção, no caso dos humanos, ainda que essa sensação fosse notadamente enfraquecida, apareciam contornos dessa reação que não condiziam propriamente com o estado de estar emocionado. Esse ponto será tratado mais adiante.

Agora é importante esclarecer um paradoxo que segundo Vigotski (2003) surgiu dessas séries de experimentações. Se a manifestação emocional prescinde da reação corporal e se mantém mesmo quando esta é suplantada, para que serviriam então tão profundas mudanças? Cannon (1916) resolve esse impasse da seguinte maneira: qualquer manifestação profunda da emoção é um gatilho para a ação que se desenrolará após seu aparecimento, seja ela fuga, ataque ou repouso. Essa é uma questão, portanto, de sobrevivência e de manutenção da vida e nesse ponto especificamente ele parece concordar com as explicações darwinianas. No entanto, nelas as emoções tenderiam a um fim, e de maneira contrária para Cannon (1916), as emoções não desapareceriam, mas se transformariam pela sociabilidade característica dos grupos humanos.

Outros aspectos cruciais devem ser destacados nos trabalhos desse autor. Primeiramente o fato de ter demonstrado que o centro da vida emocional não é arcaico e nem se encontra localizado nas 
partes baixas viscerais, pelo contrário, encontra-se atrelado à complexa dinâmica cerebral e à anatômicofisiologia das funções nervosas. Disso advém outro aspecto decisivo a que chegou em suas pesquisas, a demarcação da estreitíssima relação entre emoção e demais aspectos da vida psíquica do homem.

Agora é possível retomar o ponto deixado em aberto parágrafos atrás, quanto à pesquisa dos aspectos emocionais em homens e animais realizadas por Cannon (1916). De caráter diferenciado, a emoção assume outro patamar quando analisada nos homens. Ao ser deslocada da periferia para o centro da vida psíquica, ela começou a ser compreendida na complexa dinâmica dos processos psicológicos superiores. Assim, não mais poderia ser caracterizada como um estado dentro de outro estado, mas como um aspecto da totalidade da psique humana, posição essa defendida por Vigotski (2003).

Se por um lado a compreensão de que as ciências, incluindo a psicologia, deveriam ser desenvolvidas com métodos rigorosos de controle possibilitou resultados mais fidedignos, por outro, limitou a complexidade do estudo de alguns fenômenos, dentre eles os das emoções. As pesquisas assinaladas até aqui, perfazendo parte do caminho trilhado por Vigotski apontaram apenas para um aspecto da dimensão que o autor atribuía ao fenômeno de emoção, muito mais próximo à morfofisiologia. Conforme percebeu, esses métodos utilizados nas pesquisas psicofisiológicas criaram algumas dificuldades para se estudar a vida emocional. Uma delas foi a de desdobrá-las em dois planos: um da vida vegetativa e outro dos processos psicológicos superiores - e esses últimos, até a teoria cannoniana, praticamente não foram estudados. Assim permanecia em aberto o campo da investigação clínica, que será pioneiramente explorado pela psicanálise.

$\mathrm{Na}$ contramão dos pesquisadores daquele momento, Freud (1987) se propõe estudar as emoções negando que o componente orgânico seja seu único fundamento. Para isso, ele partiu da psicopatologia da vida cotidiana, demonstrando que tomar a reação orgânica da emoção como objeto de estudo não significava abarcar a totalidade desse fenômeno. Há, para ele, na dinâmica da vida emocional um complexo desenvolvimento que se dá, não nos centros nervosos - embora ele tenha inicialmente se proposto a estudálos-, mas nos desejos sexuais, sejam eles reprimidos ou não. Com isso Freud (1987) demonstrou a ambivalência das emoções, sobretudo nos primeiros anos de vida do sujeito, mostrando que um desejo não atendido ou reprimido pode se transformar qualitativamente noutra forma de expressão de uma emoção.

Com a agudeza de seu estudo, a psicanálise freudiana aprofunda a compreensão de que as emoções, além de instáveis e antitéticas, possuem uma gênese, uma história e desenvolvimento, e que no decorrer da vida do indivíduo, ela está passível de períodos de evolução e de crise. Assim, ele não só pesquisa de forma diferenciada a emoção, como também cria essa nova forma de pesquisá-la. E em que consistiu essa nova forma? Significou tomá-la dentro da dinâmica da vida psíquica, sem separar os aspectos orgânicos dos psicológicos, como fizeram os fisiologistas nos laboratórios, que comprendiam a emoção como um estado dentro de outro.

Alguns limites devem, contudo, ser apresentados em suas concepções. O primeiro deles destacado por Vigotski (2003) é o de assumir a sexualidade como a pedra angular para a psicanálise, reduzindo toda a dinâmica da vida emocional a esse aspecto e, por conseguinte, toda a vida psíquica. O segundo limite jaz exatamente naquilo que ela pretendeu negar: o naturalismo. Isso porque, na teoria psicanalista, o desenvolvimento psicológico ocorreria por uma força de mesma ordem que compele a todos os indivíduos igualmente. O que ocorre em Freud, porém, é que ao se opor a James-Lange, ele não tem os processos fisiológicos como seus determinantes e por isso precisa recorrer à metafísica dos mitos. Essa postura criou dissensões dentro da psicanálise, onde alguns psicanalistas optaram em enfatizar mais os aspectos sociais para a compreensão da gênese dos processos psíquicos, como o fez a proposta adleriana.

Adler(1992/1931) viu a emoção como componente indissociável dos momentos de constituição da personalidade, mas por vezes oscilava entre assumila como instintiva ou psicológica superior, levando-o também a recorrer a explicações mitológicas. Em sua obra What Life Should Mean to You, todavia, essa teoria se propõe a colocar a psique e o corpo no mesmo plano, pelo viés das emoções, agora elevadas à posição e função de destaques. Sobre esse fato, Vigotski (2003, p.97) afirma que enquanto nas teorias anteriores a emoção atuava como uma "surpreendente exceção, uma tribo agonizante", agora ela passou a estar relacionada com toda a formação da estrutura psicológica fundamental da personalidade.

Se a psicanálise freudiana assumiu a sexualidade como um princípio geral que orienta o prazer e o desenvolvimento psicossocial, para Adler (1992/1931) este princípio estava na superação do sentimento de inferioridade, promovido pelo self criador, conforme Hall e Lindzey (1973). Aparentemente Adler discordava da proposta freudiana, entretanto, nesse ponto a confirma, porque não abdicou do princípio do prazer, embora o deslocou para o interesse social futuro do infante, rompendo com a rígida determinação das experiências da primeira infância conforme esta figurava na teoria freudiana. Percebendo esse limite, mas concordando que o círculo da vida emocional participa efetivamente da constituição da identidade também na fase adulta, Vigotski (2003) analisou o trabalho de outro autor que investigou, por meio de pesquisa com crianças, o princípio do prazer. Seu 
nome é Karl Bühler.

Tecendo uma crítica ao tratamento dado por Freud às emoções e aos sentimentos em seu trabalho, o psicólogo gestaltista Bühler (as cited in Vigotski, 2003), não só questionou a determinação da vida psíquica da criança estar regida pelo princípio do prazer, mas demonstrou experimentalmente que o próprio prazer que impulsiona a crianças à atividade muda de lugar no sistema de outras funções psíquicas. Para isso ele propôs diversos experimentos com crianças e foi conduzido à conclusão que a experiência emocional divide-se e evolui em três etapas: a primeira é que o prazer persegue sua satisfação imediata, que é acompanhada de uma manifestação emocional resolutória, a ela correspondente, Endlust (prazer final), como ocorre com a busca do prazer no ato sexual; na segunda, o prazer é deslocado para o processo de sua atividade e durante esse período aparecem os traços emotivos, Funktionslust (prazer funcional); já a terceira, Vorlust (antecipação do prazer), a manifestação emocional oriunda do prazer encontra-se no início da atividade, como ocorre por exemplos nos jogos de adivinhação. $\mathrm{O}$ redirecionamento dos centros que produzem essas sensações de prazer coincide com a atividade predominante desempenhada pela criança em dada faixa etária, o que constitui a formação do hábito. Este então encontrará suporte não necessariamente no resultado da ação, mas na ação em si.

Assim, o resultado a que chegou em suas pesquisas expõe de que maneira a emoção ou o sentimento, outrora estudada apenas com ponto de apoio quase eminentemente biológico, Endlust, transforma-se gradativamente num processo psicológico superior, Vorlust, além de enfatizar a dinâmica do movimento desse prazer. Tais resultados chamaram a atenção de Vigotski (2003), embora ele os qualifique como "um pálido reflexo da expressão de toda a diversidade possível na vida emocional" (p. 100). Destarte, os dados de Bühler anuam com a função da atividade na constituição da emoção enquanto manifestação psicológica superior, em conformidade com os aspectos dos pressupostos teóricos da psicologia vigotskiana.

Outro teórico que se ocupou da vida infantil, tanto daquelas crianças normais como das anormais, combinando seu estudo com o de pessoas adultas, foi o suíço Claparède (1873-1940). Até então, a emoção era tomada como sinônimo para sentimento e vice-versa. É mérito desse suíço a compreensão de que, embora na aparência elas sejam semelhantes, na essência estas se distingam e por vezes, de maneira contraditória. Se, conforme defendiam os darwinistas ainda que de maneira bastante simplificada, a emoção serviria à proteção e, como demonstrou Cannon (1916), ela prepararia o corpo para a execução de uma ação, o que dizer daquela reação paralisadora que muitas vezes compromete a própria ação e a inviabiliza? Por outro lado, se cabe à emoção a função de corruptora da vida psíquica, de que maneira o homem decidiria entre essa ou aquela ação ao se deparar com uma situação de perigo? Caso se confrontasse um problema com o outro, a vida emocional vegetativa explicaria a dinâmica da consciência, mas não explicaria a si mesma enquanto um fenômeno psicológico superior. Talvez por isso Freud tivesse recorrido em algum momento a uma explicação topológica por instâncias.

$\mathrm{O}$ arguto Claparède (as cited in Feinstein, Duff e Tranel, 2010), percebendo a encruzilhada a que chegou a teoria freudiana, buscou respostas na dinâmica da própria emoção: naquilo que a produz e naquilo que ela mesma produz. Por exemplo, conforme a teoria biologicista mostra, se a emoção for reduzida a sua função biológica, como explicar a gama crescente de emoções que acompanham o desenvolvimento histórico? Ou no caso da teoria freudiana como essa função afetaria toda a vida psíquica determinando seu avanço? A pretensa função de proteção poderia ser questionada ao se tomar aqueles eventos em que o organismo paralisa-se frente à ameaça, ao invés de promover fuga ou ataque. E no caso do homem, aquele que souber de antemão do perigo responderá de forma diferenciada daquele que o desconhece. Então a resposta orgânica não pode ser destacada do aspecto psicológico que a engendra, e essa reação será de duas ordens: uma emotiva/conativa, imediata e a outra de caráter sentimental/motivada, superior. Embora ambas contenham aspectos biológicos e sociais intrínsecos, no segundo caso há a permanência da sensação advinda da experiência, bem como a possibilidade de previsão e controle da ação.

Para ilustrar essa afirmação, pode-se tomar como exemplo o conhecido experimento em que Claparède (as cited in Feinstein e outros 2010), cumprimentou uma paciente amnésica e entre seus dedos há um alfinete. Na próxima vez em que foi cumprimentá-la, a paciente estendeu a mão e rapidamente a recolheu, sem se lembrar do evento anterior, e por alguma razão não cumprimentou Claparède. Os dois eventos embora induzam à mesma resposta (cumprimentar) indicaram sua dissociação, onde a lembrança não consciente do evento anterior foi um fator crucial para a resposta diferenciada do segundo caso.

Por meio dessas pesquisas o suíço chega então à diferenciação entre sentimento e emoção, onde para aquele há uma elaboração mental prévia da resposta, enquanto nessa última há a carência dessa elaboração. Aparentemente as manifestações exteriorizadas podem ser as mesmas, mas quando se considera as circunstâncias, as passagens e os momentos na elaboração dessas manifestações, percebe-se que são qualitativamente diferentes.

No mesmo sentido das pesquisas de Claparède, Lewin (1935) buscou explicar experimentalmente a complexa dinâmica da vida emocional, desbancando a pretensa "profundidade psicológica" (Vigotski, 
2003, p. 102) dos psicanalistas Freud e Adler, uma vez que eles descartaram seu estudo experimental. Em sua obra A Dynamic Theory of Personality, Lewin (1935) mostrou a dinâmica dos estados emocionais e como uma sensação emocional não resolvida, se oculta, e permanece existindo. Os estados afetivos não são, para ele, traços que se associam com outros aspectos psicológicos, mas sim uma estrutura concreta desse processo, ainda que aparentemente ausente de emoção. Mesmo as atividades eminentemente intelectuais estão imbricadas na dinâmica da emoção - ela não é parte do processo, mas se constitui e se dinamiza no todo do processo.

Para Lewin (1935) as emoções não estão associadas ou dissociadas desse ou daquele aspecto, mas se constituem na integralidade de todo o processo psicológico. Assumindo a mesma direção, a teoria vigotskiana trará à discussão, de forma sumária, de um lado as recentes conclusões das neurociências daquele momento e de outro, a psicopatologia. Na primeira, ela mostrará que a emoção possui centros nervosos no cérebro, mas que nem sempre correspondem de forma direta a uma dada resposta ou que aquilo que sinalizam externamente, nem sempre representa um estado psicológico. A senso-percepção pode ser confusa e aferir reações emocionais estranhas e aparentemente disjuntivas, caso os centros nervosos córtico-subcorticais estejam prejudicados.

Por meio do exposto acima, Vigotski (2003) demonstra que partindo da senso-percepção, desde seu momento inicial de afecção até sua significação e resposta comportamental, a emoção constitui e integraliza todo o processo. Em alguns quadros patológicos como no pensamento autista, no entanto, a emoção dirige todo esse processo, enquanto no pensamento realista a direção seria efetuada pelo pensamento. Outro ponto ainda nas patologias, é que a emoção é subvertida podendo constituir sentimentos de outra ordem.

\section{Considerações Finais: Um Retorno à Emoção}

A teoria dos sentimentos e das emoções fora considerada por Vigotski (2003b) “o capítulo menos elaborado da psicologia tradicional" (p.114). Para ele seria mais difícil, dentro do campo psicológico, estabelecer critérios para descrição, análise, vinculação e classificação nessa área, do que em qualquer outra na psicologia. A dicotomia entre pensamento e afetividade entravou e ainda limita as pesquisas em psicologia, posto que impede a compreensão tanto da gênese como do desenvolvimento da subjetividade e de seu reflexo sobre a saúde, considerando que a emoção pode ser somatizada.

Assim, embora as pesquisas nesse campo tenham caminhado ao considerarem seus aspectos culturais e a emoção tenha deixado de ser um estado no corpo para tornar-se o estado do corpo, a cisão entre pensamento e afeto tem se mantido. Essa separação dificulta a compreensão da Psicologia enquanto uma ciência preocupada com a saúde como dimensão integral do psiquismo, fazendo com que alguns autores claudiquem na busca de aprofundamento dos aspectos biopsicofisiológicos dos fenômenos psicológicos e neuropsicológicos, uma vez que os dicotomizam, como faz Damásio (1996) e Lutz (1988).

Essa cisão acaba por espraiar-se para outras práticas, como as do cotidiano escolar, apontada por Leite (2006) e Arantes (2003), onde o intelecto é supervalorizado em detrimento do afeto, cabendo a este último a posição de representante de uma patologia que se superporia à razão. Embora a emoção funcione como antitética ao pensamento, como apontou Vigotski (1999), ela não o rebaixa, mas sim o constitui dialéticamente.

Tal inter-relação só pode dar-se diante de um elemento mediacional, a saber, o da cultura, traduzido e encarnado pela consciência e não como simples interação, como propunha Damásio (1996), que faz uma passagem imediata entre as duas instâncias, abdicando do elemento mediacional, diretor da dialética dessa relação.

Pelo caráter histórico-social da teoria vigotskiana, o fenômeno deve ser buscado na dimensão histórica de sua construção bem como na função que ele passa a exercer nas condições reais de vida, tendo em vista que a atividade constitui as funções psicológicas superiores. Assim sendo, além do nexo causal e funcional, a emoção deve ser abarcada naquilo que ela representa como um determinado estado psíquico, na especificidade de um dado momento social. Nessa perspectiva, ela deixa de ser um substrato, resquício de uma vida ancestral e passa a assumir uma dimensão atualizada, contemporânea, que se expressa na e que é expressão de saúde, uma vez que se configura como uma linguagem e como um sintoma. Depreende-se também que enquanto função, seu papel é de "direção e orientação das reações" (Vigotski, 2003b, p. 118) e de "organizador interno dessas reações" (idem), e não de desajuste e desencontro, como querem algumas teorias atuais como as de Goleman (1995), sobre tipos de inteligência.

Investigar a emoção, o sentimento e o afeto é contrapor-se a determinados aspectos históricosociais, dentre os quais se destacam alguns elementos supervalorizados no sistema capitalista, como por exemplo o do cálculo frio, que promovem uma conotação negativa que a sociedade, inclusive a científica, atribui às emoções. Tal fato verifica-se: pelo lugar subalterno a ela reservado no decurso da história social; pela supervalorização da dimensão racional para a contabilização da mais-valia; pelos avanços e prevalência dos estudos da linguagem de programação computacional que abdica do aspecto emocional, sentido, que a linguagem encerra; pelo tratamento secular a ela atribuído por algumas escolas 
da psicologia; para citar apenas alguns fatores.

Assim, ao mesmo tempo em que é preterida pelas ciências, ela rende muitos dividendos para aqueles que a tomam como objeto de análise, seja para rechaçá-la, seja para valorizá-la. Isso poderia indicar a recuperação de um conceito atravessado por contradições e que exige um grande empenho em sua investigação, uma vez que ela está imbricada ao conceito e sentido da saúde. Mas, segundo Sawaia (2010), isso não deve exprimir o desejo de investigar as emoções com receitas rápidas como fast-foods, nem de medicalizá-las antes de compreendê-las ou analisá-las.

Nesta direção, a necessidade de estudar as emoções não pode ser confundida com uma política de subjugação da mesma. As emoções dão o colorido da vida e por meio delas podemos compreender como a realidade nos afeta e como podemos agir sobre essa realidade em busca das satisfações de nossas necessidades e melhoria de qualidade de vida; é por meio delas que estabelecemos relações com os demais sujeitos e com o ambiente em que nos inserimos e também são elas (embora, seja necessário que se frise, não exclusivamente) as responsáveis pela configuração de nossa identidade e da forma com que nos colocamos no mundo. É o que nos indicam as pesquisas empreendidas por Vigotski e que se contrapõem àquela concepção de um pensamento que deve ser controlado pela razão, e que despreza os aspectos somáticos e salutares do corpo.

\section{Referências}

Adler, A. (1931/1992). What life should mean to you, (1a.ed). Oxford: Oneword Publications.

Arantes, V.A. (Org.) (2003). Afetividade na escola: alternativas teóricas e práticas, (3a.ed). São Paulo: Summus.

Bell, B. (1930). The nervous system of the human body, (1a. ed). Acessado de http://books.google.com.au/books/about/The Nervous_System_of the_Human_Body.html?id=MallccGtlCIC

Belli, S. e Iñiguez-Rueda, L. (2008). El estudio psicosocial de las emociones: una revisión y discusión de la investigación actual. Psico 39 (2), 139-151, abril/junho. Ed. Puc: RS. Acessado de http:// revistaseletronicas.pucrs.br/ojs/index.php/revistapsico/article/ viewFile $/ 4019 / 3034$

Cannon, W. B. (1916). Bodily changes in pain, hunger, fear and rage: an accout of recerches into the function of emotional excitement, (1a.ed) [Versão eletrônica].

Cornelius, R. R. (2000). Theoretical approches to emotion. ITRW on Speech and Emotion. ISCA Archive, Newcastle, Northem Ireland, UK. Acessado de http://www1.cs.columbia.edu/ julia/ papers/cornelius00.pdf

Damásio, A. (2004). Em busca de Espinosa: prazer e dor na ciência dos sentimentos, (1a.ed). São Paulo: Companhia das Letras.

Darwin, C. (1902). La expresión de las emociones: en el hombre y en los animales. Tomo I. (1a.ed) [Versão eletrônica] Francisco Sempere y C.a, Editores.-Valencia. Sevilla.

Feinstein, J. S.; Duff, M. C.; Tranel, D. (2010). Sustained experience of emotion after loss of memory in patients with amnesia. Proceedings of the National Academy of Sciences, 107 (17), 7674-7679.

Freud, S. (1987/1901). A psicopatologia da vida cotidiana- vol. VI. Edição Standard Brasileira das Obras Psicológicas Completas. Rio de Janeiro: Imago.
Hall, c. S. e Lindzey (1973). Teorias da personalidade (14a.ed). São Paulo: Ed. Pedagógica e Universitária Ltda.

Leite, S. A. S. (Org.). (2006). Afetividade e práticas pedagógicas (1a.ed). São Paulo: Casa do Psicólogo.

Lewin, K. (1935). A dynamic theory of personality. McgrawHill Book Company, Inc, New York and London.

Lutz, C. (1988). Unnatural Emotions: Everyday Sentiments on a Micronesian Atoll and Their Challenge to Western Theory. University of Chicago. Acessado de http:// books.google.com.br/books/about/Unnatural_Emotions. html?id=EJGQpqhxNVsC\&redir_esc=y

Neubern, Maurício S (2000). As emoções como caminho para uma epistemologia complexa da psicologia. In: Psicologia: Teoria e pesquisa. Mai/ago, 16 (2), 153-164. UNB-Brasília.

Pinto, A. C. (1998). O impacto das emoções na memória: alguns temas em análise. Psicologia Educação e Cultura. 2(2), 215-240. Faculdade de Psicologia e de Ciências da Educação, Universidade do Porto. Acessado de http://www.fpce.up.pt/docentes/acpinto/ artigos/11 memoria e emocoes.pdf

Sawaīa, B.B. (2010). A emoção como lócus de produção do conhecimento - uma reflexão inspirada em Vygotsky e seu diálogo com Espinosa. Anais da III CONFERÊNCIA DE PESQUISA SÓCIO-CULTURAL. Campinas.

Vigotski, L.S. (1999). A tragédia de Hamlet, príncipe da Dinamarca, (1a.ed). São Paulo: Martins Fontes.

Vigotski, L.S. (2003). O desenvolvimento Psicológico na Infância, (1a.ed). São Paulo: Martins Fontes.

Vigotski, L.S. (2003b). Psicologia Pedagógica, (1a.ed). São Paulo: Artmed.

Vigotski, L.S. (2004). Teoria e método em psicologia, (3a.ed). São Paulo: Martins Fontes.

Vigotski, L.S. (2004b). Teoría de las emociones - Estudio histórico-psicológico, (2a.ed). Madrid: Ediciones Akal.

Vigotski, L.S. (2010). A construção do pensamento e da linguagem, (2a.ed). São Paulo: Martins Fontes.

Recebido: $31 / 03 / 2014$

Última revisão: 19/05/2015 Aceite final: 22/05/2015 
Sobre os autores:

Heriel Luz - Mestre em Psicologia pela Universidade Federal de Mato Grosso do Sul. E-mail: herielluz@gmail.com.

Ana Lucia Martins de Souza - Mestre em Psicologia pela Universidade Federal de Mato Grosso do Sul. E-mail: ana.souza@ufms.br.

Lívia Gomes dos Santos - Mestre em Educação pela Universidade Federal de Mato Grosso do Sul e doutoranda na Pontifícia Universidade Católica de São Paulo.

E-mail: liviagomess@hotmail.com. 